\title{
The Effect of $2 \%$ Chlorhexidine on the Bond Strength of Two Different Obturating Materials
}

\author{
${ }^{1} \mathrm{~K}$ Dinesh, ${ }^{2}$ BV Sreenivasa Murthy, ${ }^{3}$ Indiresha H Narayana, ${ }^{4}$ Swaroop Hegde, ${ }^{5} \mathrm{KS}$ Madhu, ${ }^{6}$ Shruthi Nagaraja
}

\begin{abstract}
The bond strength of ActiV GP and gutta-percha/AH Plus after using $2 \% \mathrm{CHX}$ as final rinse was evaluated in this study. According to the final irrigation regimen forty roots were divided into two groups $(n=20)$ randomly: Group $1-5 \mathrm{ml}$ of $17 \%$ EDTA; Group $2-5 \mathrm{ml}$ of $17 \%$ EDTA followed by $5 \mathrm{ml}$ of $2 \%$ chlorhexidine gluconate $(\mathrm{CHX})$. Based on the obturation system the two groups were further subdivided into two subgroups $(n=10)$. The roots were horizontally sectioned from the coronal and midthird sections for measuring the push-out bond strength. $\mathrm{CHX/AH}$ Plus $(2.795 \pm 0.42 \mathrm{MPa})$ and EDTA/ActiV GP $(1.489 \pm 0.117$ $\mathrm{MPa}$ ) recorded the highest and lowest mean bond strength values respectively. It was concluded that when $2 \% \mathrm{CHX}$ was used as a final irrigation rinse the bond strength of both guttapercha/AH Plus and ActiV GP obturation system improved significantly.
\end{abstract}

Keywords: ActiV GP, AH Plus, Bond strength, Chlorhexidine. How to cite this article: Dinesh K, Murthy BVS, Narayana IH, Hegde S, Madhu SK, Nagaraja S. The Effect of $2 \%$ Chlorhexidine on the Bond Strength of Two Different Obturating Materials. J Contemp Dent Pract 2014;15(1):82-85.

Source of support: Nil

Conflict of interest: None declared

\section{INTRODUCTION}

Successful endodontic therapy aims at not only complete deb-ridment of the root canal system, but also three-dimensional obturation of the canal space. ${ }^{1}$ Mechanical instrumentation results in smear layer formation that plugs the dentinal tubules, which has to be removed to obtain a better seal. The potential advantage of using EDTA and $\mathrm{NaOCl}$ alternatively has been substantiated, but their combination lacks the antimicrobial capacity and substantivity. ${ }^{2,3}$ This resulted in introduction of $\mathrm{CHX}$ as an alternative irrigating solution to $\mathrm{NaOCL}$ which has antimicrobial action, substantivity and

\footnotetext{
${ }^{1,5}$ Senior Lecturer, ${ }^{2}$ Principal and Senior Professor

${ }^{3}$ Associate Professor, ${ }^{4}$ Professor, ${ }^{6}$ Assistant Professor

${ }^{1-6}$ Department of Conservative Dentistry and Endodontics MS Ramaiah Dental College and Hospital, MSR Nagara MSRIT Post, Bengaluru, Karnataka, India

Corresponding Author: K Dinesh, Senior Lecturer Department of Conservative Dentistry and Endodontics MS Ramaiah Dental College and Hospital, MSR Nagara MSRIT Post, Bengaluru, Karnataka, India, Phone: 9611711884 e-mail: drdini21@gmail.com
}

less tissue toxicity. ${ }^{4}$ The property of CHX being a cationic bisbiguanide seems to act by adsorbing onto the cell wall of microorganism resulting in leakage of intercellular components. At lower concentrations it has bacteriostatic and at high concentrations it has bactericidal effects and also has been reported to have a substantivity of 8 to 12 weeks due to its ability to bind to hydroxyapatite crystals. ${ }^{5,6}$

Among the required physical properties of filling materials, adhesion was found to be a desirable property in root canal cements. ${ }^{7}$ To achieve complete seal, the root canal filling materials should adhere to the dentinal walls and prevent the seepage of fluids in between filling and canal walls. ${ }^{8} \mathrm{AH}$ Plus has been slowly replacing the other contemporary sealer due to its desirable physical properties, reduced solubility, apical sealability, improved micro retention to root dentin and biocompatibility. $^{9}$

ActiV GP Precision obturation (Brasseler USA), being a new glass ionomer based material, where the gutta-percha is impregnated and surface coated with glass ionomer particles. The efficiency of the binding of ActiV GP as core material to the intraradicular dentin will be enhanced by the use of GIC sealer. ${ }^{10,11}$ Even though earlier studies on the bonding and adaptation of ActiV GP to root canal dentin is available but the effect of $2 \%$ CHX on the sealer-dentin bond strength when using ActiV GP obturation system is limited. Therefore, the aim of the study was to assess the effect of $2 \% \mathrm{CHX}$ on the bond strength of gutta-percha/AH Plus and ActiV GP obturation system.

\section{MATERIALS AND METHODS}

Forty recently extracted human single-rooted teeth were used in this study. The selected teeth were cleaned and stored in distilled water. The teeth were decoronated into approximately $16 \mathrm{~mm}$ long root segments using high speed carbide bur. Canal patency followed by working length was established by inserting \#15 K-file (Mani). The root canals were instrumented using $\mathrm{K} 3$ nickel-titanium rotary instruments (Sybron Endo) and was enlarged to size $40 \mathrm{~K} 3$ 0.06 taper till the working length and irrigated using $5 \mathrm{ml}$ of $3 \%$ sodium hypochlorite between each file.

Two groups $(n=20)$ were made from specimens following instrumentation based on the final irrigation regimen: Group A—5 ml of 17\% EDTA(INSTA); Group B, 
$5 \mathrm{ml} \mathrm{17 \%} \mathrm{EDTA} \mathrm{followed} \mathrm{by} 5 \mathrm{ml}$ of $2 \%$ CHX. Paper points was used to dry the canals; the groups were further subdivided into two subgroups based on the Obturating Systems.

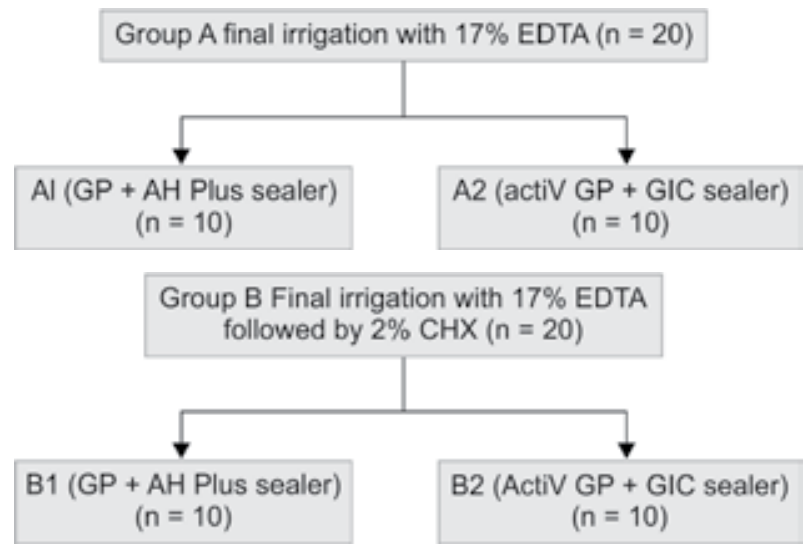

In the first subgroup (A1 and B1), the root canals were obturated using thermoplasticized gutta-percha and AH Plus sealer (Dentsply). Both canal and master cone \#40/0.06 was coated with sealer and inserted up to the working length. Gutta-percha was condensed within $5 \mathrm{~mm}$ from the working length using fine medium System B plugger. Coronal and middle third of the canals were then back filled with thermoplasticized obturation technique using Elements obturation system (Sybron Endo).

In other subgroup (A2 and B2) canal and master cone, \#40 size 0.06 taper ActiV GP was coated with sealer (Glass ionomer based) and inserted to determined length and excess was sheared using System B plugger.

To ensure complete setting of the sealers, specimens were stored in $100 \%$ humidity for 48 hours. They were coded and embedded in an autopolymerizing acrylic resin followed by which three horizontal sections of $2 \mathrm{~mm}$ thickness were made from coronal and middle third using hard tissue microtome resulting in 30 horizontal sections per subgroup.

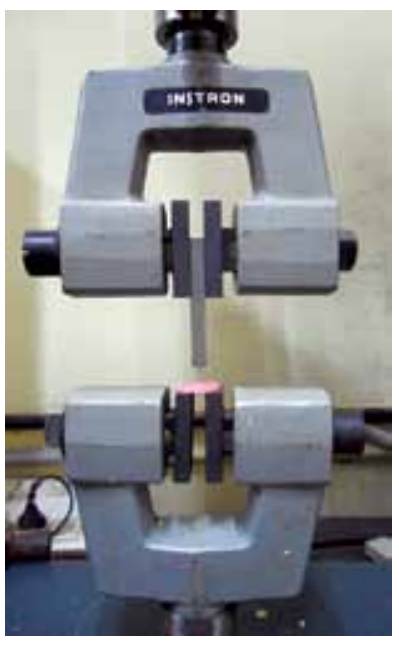

Fig. 1: Measurement of pushout bond strength using Instron Universal Testing Machine
The slices were kept moist in a container filled with saline and the order of slices (from coronal to apical) as well as each slice's apical side was identified by coding them with the help of a marker. Each slice was then positioned under Zeiss Stereomicroscope where the diameter of each obturation site was measured and pictures of both sides of each slice were taken with digital camera (Olympus 5010) with the help of Image Proplus Software.

The specimens were attached to a support jig of the Instron Universal Testing Machine (Zeiss 500) with the apical end facing the load cell and coronal facing the support jig. The punch was affixed to the crosshead to contact the apical part of the specimen in Figure 1. Compressive load was applied at a crosshead speed of $1 \mathrm{~mm}$ per min until the extrusion of the obturation from the specimen, this was manifested by a sudden drop along load deflection on a graph, the highest point in the graph was measured as maximum compressive load for that sample.

Push-out bond strength $(\mathrm{MPa})=$

$$
\text { Maximum load }(\mathrm{N})
$$

Adhesion area of root canal filling $\left(\mathrm{mm}^{2}\right)$

Statistical analysis was done by using student ' $t$ ' test.

\section{RESULTS}

The mean values recorded for different groups are presented in Figure 2 and for different subgroups in Figure 3. Group B (CHX) recorded better bond strength between the two groups and the highest mean bond strength $(2.795 \pm 0.422 \mathrm{MPa})$ was recorded for subgroup B1 (CHX/AH Plus and lowest $(1.489 \pm 0.117 \mathrm{MPa})$ was recorded for subgroup A2 (EDTA/ Activ GP). The remaining two subgroups yielded intermediate values of bond strength, i.e. $1.892 \pm 0.113 \mathrm{MPa}$ for subgroup A1 (EDTA/AH Plus) and 2.278 $\pm 0.164 \mathrm{MPa}$ for subgroup B2 (CHX/Activ GP) respectively.

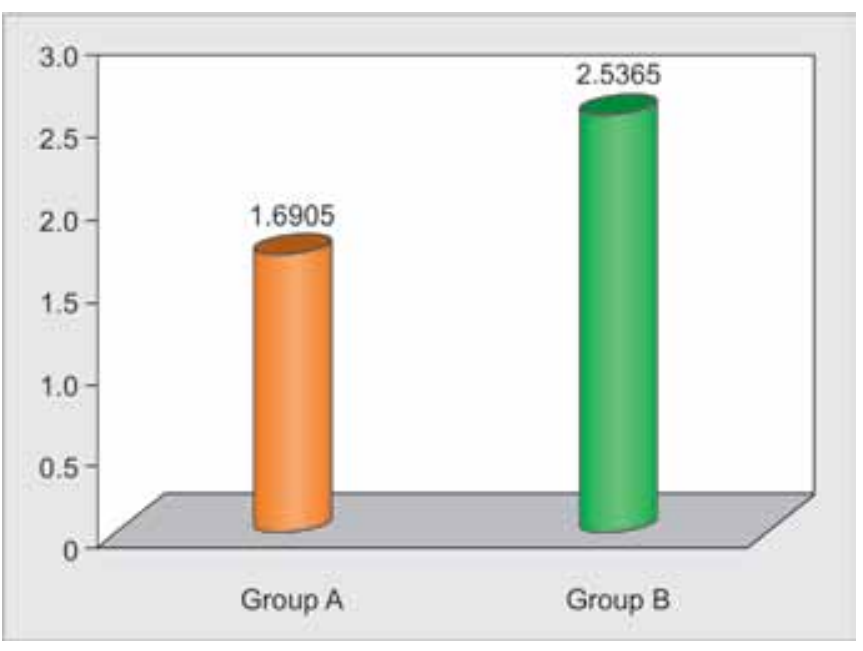

Fig. 2: The comparison of mean bond strength between groups A and B 


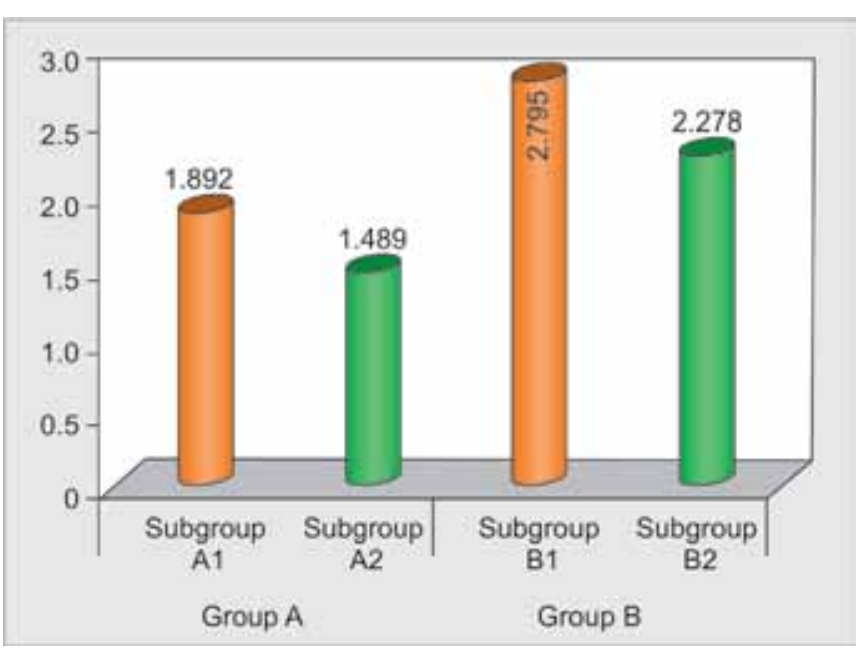

Fig. 3: Mean values recorded for different subgroups

\section{DISCUSSION}

Alteration in the chemical and structural composition of dentin caused by using different irrigation regimens results in altered permeability and solubility characteristics. ${ }^{12,13}$

These properties affect the bonding of materials to the dentin surface. ${ }^{14}$ The clinical longevity of endodontically treated tooth depends on the effective adhesion of the obturating material to the dentin.

In the present study, it was found that the irrigation regimens influences the bond strength of the tested obturation systems. The group in which CHX was used as a final irrigation rinse yielded better bond strength compared to EDTA group, this is in agreement with the studies done by Ahmed et al. ${ }^{15}$ The higher bond strength obtained with CHX group for both the obturation systems could be attributed to various factors. CHX gets adsorbed into the root dentin and released as long as 48 to 72 hours after irrigation; this could have favored resin infiltration into dentinal tubules and have a positive effect on the bond strength. ${ }^{9}$ Presence of certain oil based components in AH Plus may prevent the complete wetting of root canal wall, resulting in poor adaptation of the material to the canal wall. Presence of surfactant in the CHX irrigant nullifies the effect of these components but increases the dentin surface energy and hence its wettability. This property is required for the adhesion of hydrophilic materials like ActiV GP to the tooth. ${ }^{15}$ Other reason for this could be that $\mathrm{CHX}$ enhances the cationic charging of the dentin surface, thus increasing the reaction of polycarboxylic group of the glass ionomer. In addition, the chemical adhesion of the ActiV GP (a diffusion-based adhesion) is due to the ion exchange property between the glass-ionomer and the tooth surface. ${ }^{16,17}$

When subgroup A1 (EDTA/AH Plus) and A2 (EDTA/ ActiV GP) obturation systems were compared with regards to EDTA as a final rinse there was no statistically significant difference between the subgroups. However, subgroup A1 (EDTA/AH Plus) yielded better bond strength in comparison to subgroup A2 (EDTA with ActiV GP) which is in agreement with study done by Sly et al. ${ }^{18}$ EDTA decreases the wetting ability of dentin (i.e. reduced surface energy). Therefore, suitable dentin substrate like resinous AH Plus could be provided for the adhesion of hydrophobic materials. ${ }^{19,20}$ On the contrary, such decreased wetting ability of dentin surface treated with $17 \%$ EDTA may have prohibited the adhesion of hydrophilic materials like ActiV GP.

EDTA is a powerful anti-oxidant via redox reaction, it allows free radical polymerization without premature chain termination and allows complete polymerization of resins and enhances the resin sealer-dentin bond strength. ${ }^{21}$ The property of EDTA in removing smear layer and allowing resin infiltration into the open dentinal tubules results in micromechanical retention.

When bond strength of two different obturation systems in group B were compared, subgroup B1 yielded better bond strength which may be due to the synthetic protease inhibition by CHX which results in better wettability, penetration and also provides a suitable substrate for resin adhesion. ${ }^{22,23}$

\section{CONCLUSION}

Within the limitations of the study, it could be concluded that: (1) The use of $2 \% \mathrm{CHX}$ as a final rinse following $17 \%$ EDTA significantly improved the bond strength of both gutta-percha/AH Plus and ActiV GP obturation system, (2) When bond strength of gutta-percha/AH Plus and ActiV GP obturation system were compared, gutta-percha/AH Plus recorded the highest mean bond strength amongst the two obturation systems.

\section{REFERENCES}

1. Shipper G, Ørstavik D, Teixeria FB, et al. An evaluation of microbial leakage in roots filled with a thermoplastic synthetic polymer-based root canal filling material (Resilon). J Endod 2004;30:342-347.

2. $\mathrm{Hu}$ " lsmann M, Heckendorff M, Lennon A. Chelating agents in root canal treatment. Mode of action and indications for their use. Int Endod J 2003;36:810-830.

3. Torabinejad M, Cho Y, Khademi AA, et al. The effect of various concentrations of sodium hypochlorite on the ability of MTAD to remove the smear layer. J Endod 2003;29:233-239.

4. Wang CS, Arnold RR, Trope M, et al. Clinical efficiency of $2 \%$ chlorhexidine gel in reducing intracanal bacteria. J Endod 2007; 33:1283-1289.

5. White RR, Hays GL, Janer LR. Residual antimicrobial activity after canal irrigation with chlorhexidine. J Endod 1997;23:229231.

6. Rosenthal S, Spangberg L, Safavi KE. Chlorhexidine substantivity in root canal dentin. Oral Surg Oral Med Oral Pathol Oral Radiol Endod 2004;98:488-492. 
7. Tagger M, Tagger E, Tjan AH, et al. Measurement of adhesion of endodontic sealers to dentin. J Endod 2002;28:351-354.

8. Orstavik D, Eriksen HM, Beyer-Olsen. Adhesive properties and leakage of root canal sealers in vitro. Int Endod J 1983;16:59-63.

9. Zemner O, Spielberg C, Lamberghini F, et al. Sealing properties of a new epoxy resin based root-canal sealer. Int Endod J 1997; 30:332-334.

10. Fisher MA, Berzins DW, Bahcall JK. An in vitro comparison of bond strength of various obturation materials to root canal dentin using a push-out test design. J Endod 2007;33:856-858.

11. Donadio M, Jiang J, Safavi KE, et al. Cytotoxicity evaluation of ActiV GP and Resilon cones in vitro. Oral Surg Oral Med Oral Pathol Oral Radiol Endod 2008;106:76-79.

12. Van Meerbeek B, Lambrecht $P$, Inokoshi S, et al. Factors affecting adhesion to mineralized tissues. Oper Dent 1992;5:111-124.

13. Dogan H, Oalt S. Effects of chelating agents and sodium hypochlorite on mineral content of root dentin. J Endod 2001;27: 578-580.

14. Erickson RL. Surface interactions of dentin adhesive materials. Oper Dent 1992;5:81-94.

15. Hashem AAR, Ghoneim AG, Lutfy RA, Fouda MY. The effect of different irrigating solutions on bond strength of two root canal-filling systems. J Endod 2009;35:537-540.
16. Fardal O, Turnbull RS. A review of the literature on use of chlorhexidine in dentistry. J Am Dent Assoc 1986;112:863-869.

17. Perdigao J, Denehy GE, Swift EJ Jr. Effects of chlorhexidine on dentin surfaces and Shear bond strengths. Am J Dent 1994;7:81-84.

18. Sly MM, Moore KB, Platt JA, et al. Push-out bond of a new endodontic obturation system (Resilon/Epiphany). J Endod 2007;33:160-162.

19. Attal JP, Asmussen E, Degrange M. Effects of surface treatment on the free surface energy of dentin. Dent Mater 1994;10: 259-264.

20. Dogan Buzoglu H, Calt S, Gümu“ sderelioglu M. Evaluation of the surface free energy on root canal dentin walls treated with chelating agents and $\mathrm{NaOCl}$. Int Endod J 2007;40:18-24.

21. Miyasak K, Nakabayashi N. Combination of EDTA conditioner and phenyl-HEMA self-etching primer for bonding to dentin. Dent Mater 1999;15:153-157.

22. Carrilho MR, Geraldeli S, Tay FR, de Goes MF, Carvalho RM, Tjaderhane L. In vivo preservation of the hybrid layer by chlorhexidine. J Dent Res 2007;86:529-533.

23. Carrilho MR, Carvalho RM, de Goes MF, di Hipolito, Geraldeli S, Tay FR. Chlorhexidine preserves dentin bond in vitro. J Dent Res 2007;86:90-94. 